\title{
Exploring Principals' Reflections of Curriculum Management Changes in South African Rural Primary Schools
}

\author{
Soane Joyce Mohapi \\ M Magano \\ M Mathipe \\ S Matlabe \\ T Mapotse \\ Continuous Professional Teacher and Community Education and Training, \\ University of South Africa; Pretoria, South Africa \\ mohapsj@unisa.ac.za
}

Doi:10.5901/mjss.2014.v5n23p1221

\begin{abstract}
The educational processes constantly change and put much pressure on principals of primary schools in South Africa. This paper explores reflections of primary school principals and challenges they encountered when implementing and managing curriculum. The reflections will be sought from grade 6 rural primary principals in Mpumalanga province. A qualitative method of inquiry was used in this paper were data was collected using individual interviews with three principals and focus group discussions with School Management Teams (SMTs) of three primary schools. Findings show that the techniques used to administer the Annual National Assessment (ANA) are problematic; the timing of administering the ANA tests poses a challenge to principals. The National guidelines indicating aspects to be covered during ANA tests are not distributed to schools. The findings imply a need for greater capacity building of principals and further research into continuous curriculum changes in South African education system
\end{abstract}

Keywords: Rural primary school, National Annual Assessment, curriculum changes

\section{Introduction}

Curriculum management is critical aspect in ensuring effective teaching and learning. There are many curriculum changes that have resulted in tremendous impact on teaching and learning in South African schools. The premise of this paper is that Department of Basic Education (DBE) may need to rethink about changes in curriculum implementation and management and how to ameliorate factors that affect learner performance. The principal might be highly developed to handle the disciplinary relationships and procedures in school management but fail to demonstrate the same degree of development when it comes to working with a specific subject curriculum. With new changes in South African education system, such as the introduction of ANA, Curriculum Assessment Policy Statement (CAPS), principals must be able to diagnose the capacity of teachers and help them to teach effectively, because a primary determinant of learner achievement is effective curriculum management and implementation, quality teaching and learning

Curriculum changes that have occurred in most South African schools have been influenced by several factors such as political influences, legal framework and learner performance. The objective of this paper was to explore principals' reflections on curriculum changes which have been implemented in primary schools and determine the challenges faced by rural primary schools 'principals when implementing these changes

\section{Significance of the Study}

The study being part of a bigger project; 500 schools' project; " "Making schools better", contributed to the body of knowledge, many articles were produced out of the project but there was no article on principals'reflections of curriculum management changes in South African rural primary schools. 


\section{Theoretical Framework}

This article is guided by the critical pedagogy theory. The critical pedagogues share a goal of academic success for each learner, manifested in the preparation and experience of children to be active citizens in a fully democratic society. For critical pedagogues, the purpose of education is for social transformation toward a fully democratic society, where each voice is shared and heard in an equal way, one critically examines oneself and one's society and one acts upon diminishing social injustices. Principals and school management teams are faced with exciting yet daunting challenges: to cope with curriculum changes in South African schools in order to prepare teachers to effectively teach each learner toward successful academic achievement

The pedagogical theories of philosopher John Dewey were introduced much earlier in the twentieth century, and within a more traditional academic context, but they share a similar focus on making education a transformative experience. Curriculum changes in South African schools are in line with the transformation processes in the country. Dewey (1983) believed the ideal classroom would be a place where learners used trial and error to develop needed skills for engaging in genuine or "ethical" democratic citizenship. Learning is a process whereby knowledge is created through the transformation of experience (Kolb 1984), this is to say curriculum changes are unavoidable.

\section{Methodology}

The study was explorative in nature and adopted a qualitative approach. Qualitative researchers believe that the task of a qualitative researcher is to acquire insight and develop understanding by the researcher getting close to the data in order to understand participants' point of view and to obtain social knowledge meaning that it is the responsibility of the researcher to make sense of the data provided by participants. Qualitative method was deemed more suitable principals' reflections could best be explored by qualitative means using focus group and individual semi structured interviews and observations. As stated by Macmillan and Schumacher (2010:1) qualitative research is more concerned with understanding the social phenomenon from the participant's perspectives.

A number of ethical issues were considered confidentiality, anonymity and privacy were respected., consent of all participants were sought, the researcher outlined the aim and purpose of the research to all participants and feedback to participants was provided, both to verify data used for analysis and to comment on interpretation

\section{Sampling Procedure}

For the bigger project 500 primary schools were purposively selected by DBE and fifteen for focus group discussion, for this study three primary schools were selected purposefully from one province by the District Director. These schools were in rural area. From each school two SMTs and a principal participated in the study.

\section{Data Collection Techniques}

Data was collected through individual interviews with principals and focus group discussion with SMTs. Macmillan and Schumacher (2006) argue that with a qualitative study a researcher collects data in a face -to-face situation by interacting with selected persons in their settings. Data was presented as a narration with words that help in the understanding of the phenomena from the participants' perspective. Interview is the predominant mode of information collection in qualitative research (De Vos et.al 2011). Questions covered aspects such as how curriculum changes impact on curriculum management is and how should be teachers guided to implement curriculum changes. Three focus group discussions were held, one at each school. They covered the implementation of National Annual Assessment and Curriculum Assessment policy statement

\section{Data Analysis and Findings}

A thematic approach was adopted to data analysis, which involved developing themes and patterns (Cuba \& Lincoln 1994). The data was analysed manually by making summaries of the accounts of participants. The following themes emerged: 


\subsection{Changes in curriculum}

South African democratic government of 1994 was faced with challenges of redress and provision of quality education. This necessitated changes in the old curriculum, the new curriculum that will empower both teachers and learners was envisaged. The participants indicated that changes in curriculum are many and not coordinated properly. The following quotes capture their perceptions:

"District officials are not doing enough to support schools to implement ANA".

"Consultation from the department on CAPS implementation is limited.

"District officials know nothing about curriculum changes in our schools"

The participants further said they are not invited to attend workshops were teachers are trained on how to implement some of the changes in the teaching of particular learning areas and this create a challenge when teachers need support from them as curriculum managers. In order to effectively implement curriculum changes in schools, the accountability and responsibility rest on the shoulders of SMTs and principals being the leader of SMT. Jansen (1998) states that school curriculum changes in some schools leave much to be desired, and this leaves most of the principals unaware of what they should manage as they have not undergone any workshop.good

\subsection{Implementing Annual National Assessment}

The following are principals' perceptions regarding national annual assessment:

- "The techniques used to administer the ANA tests are problematic.

- During ANA tests learners are invigilated by someone they do not know and this unsettles them.

- When the learners have clarity seeking questions regarding the assessment they do not feel comfortable to direct them to the unfamiliar invigilator.

- The timing of administering the ANA tests is not appropriate because ANA tests are written in term three when teachers are still battling to complete the syllabus, and ANA tests cover the entire syllabus.

- Learners are very slow when writing assessments and as a result they do not finish within the allocated time.

- The content coverage in the ANA question papers is proportionally represented.

- National guidelines of which aspects to be covered during ANA are not distributed to their province and schools.

- Tools that are used to analyse the ANA data are not reliable and trustworthy because the performance is not school specific but is judged in terms of the clustering of schools/districts".

\subsection{Principals' roles in managing curriculum changes}

The new curriculum requires teachers, SMTs and principals to work in a democratic manner to ensure quality delivery of curriculum, participants mentioned that they are challenged in terms of translating curriculum changes and reforms in to practice, due the situation they find themselves in, They are unable to provide supportive environment to teachers due to the following challenges:

"As principals we are overloaded, we do both the management and the teaching due to the shortage of teachers and this compromises their school management responsibilities.

We are not adequately capacitated to perform our roles as principals and this inadequacy impedes our efficiency and effectiveness in managing curriculum changes in schools, we are not given a platform to engage with the directives from the Department of Basic Education, we are not consulted when there are major changes within the education system, this limits our inputs on decision making on key changes affecting schools"

\section{Discussion}

The section revolved around principals' reflections of curriculum changes in rural primary Schools and how they impact on curriculum management and implementation. Principals are expected to know how to embrace curriculum changes , by so doing they are adhering to DoE policies. National and international research concur that teacher development should be classroom and curriculum base (DoE 2011). From the participants' responses, it is apparent that rural primary 
school principals are not yet ready to implement and embrace curriculum changes in South African schools. The main gap identified in this paper is that ANA administration pose a challenge, participants reported that this could be because of inadequate workshops or non-attendance of workshops.

Curriculum changes therefore require well informed principals who will lead his/her staff in managing curriculum changes.

The findings also showed that the implementation of curriculum is dependent on many factors; resources that the schools have. Hoadly and Jansen (2010) argued that resources influence the quality of teaching and learning and the degree to which the curriculum can be managed and implemented. The principals mentioned that they are overloaded because of lack of teachers who can teach the subject they are teaching

\section{Conclusion}

Taking an overview of the participants' responses, the study showed that to effectively implement curriculum changes in rural primary schools, principals should be accountable, because they are chief facilitators of curriculum. The study showed that principals are not consulted when implementing changes in curriculum and are expected to lead the way. They cannot support teachers because the support they get from district official is limited. It should be mentioned in this paper that if rural primary school principals are not supported, if their work load is not reduced and if they do not attend all curriculum workshops, it will be difficult for them to understand and implement curriculum changes in their schools .

Given South African's immense learner performance challenges in primary schools especially in the rural schools, principals should be able to make decisions that entail curriculum changes; the developmental level of the teacher is a major factor to be considered in managing curriculum. SMTs and principals just like teachers should continuously be developed for them to be able to assist teachers to manage the curriculum. Continuous development may focus on the following aspects: Managing changes in curriculum planning, monitoring, curriculum and classroom management

\section{Recommendations}

The study suggests that principals should treat teachers differently because their curriculum challenges differ. The way principals help teachers will affect the manner in which teachers teach and help learners. The quality of interaction between the principal and the school management team (SMT) and teachers may contribute towards managing curriculum changes effectively. It is therefore quite appropriate for principals to provide support and direction on curriculum changes. It will be challenging for rural primary school principal to provide the support needed by teachers and SMTs if themselves have curriculum challenges.

\section{References}

Dewey J, 1934. A Common Faith. New Haven: Yale University Press

De Vos AS, Strydom H, Fouche CB, Delport CSL 2011. Research at Grass Roots: For the Social Sciences and Human Service Professions. 2nd Edition. Pretoria: Van Schaik Publishers

Department of Education. 2009. Report of the Review of the Implementation of the National Curriculum Statement. Pretoria: Government Printer

Guba EG, Lincoln YS, 1994. Competing Paradigms in qualitative research. London: Sage

Hoadley U, Jansen J, 2010. Curriculum: Organizing Knowledge for the Classroom. South Africa: Oxford University Press.

Kolb DA, 1984. Experiential Learning: Experience as the source of Learning and Development. Englewood Cliffs, New Jersey: Prentice Hall

McMillan JH, Schumacher 2006. Research in Education- Evidence Based Inquiry USA: Pearson Education

McMillan JH, Schumacher 2010. Research in Education $7^{\text {th }}$ edition. Boston: Allen \&Bacon 